\title{
A Rare Manifestation of Cervical Yolk Sac Tumor in an Unfortunate Infant
}

\author{
Jeyasakthy Saniasiaya (D), Suzina Sheikh Ab Hamid (1), Hazama Mohamad (D), Wan Nur Najmiyah Wan \\ Case Report Abdul Wahab (iD, Norzaliana Zawawi (1) \\ Department of Otorhinolaryngology-Head and Neck Surgery, University Sains Malaysia School of Medicine, Kota Bharu, Malaysia
}

Abstract

ORCIDS ID of the authors:

J.S. 0000-0003-1974-4379;

S.S.A.H. 0000-0002-8727-6119;

H.H. 0000-0002-1447-1714;

W.N.N.W.A.W. 0000-0003-2809-6342;

N.Z. 0000-0003-3640-0383

Cite this article as: Saniasiaya J, Ab Hamid SS, Mohamad H, Wan Abdul Wahab WNN, Zawawi N. A Rare Manifestation of Cervical Yolk Sac Tumor in an Unfortunate Infant. Turk Arch Otorhinolaryngol 2019; 57(3): 157-60.

\section{This study was presented at the $4^{\text {th }}$ Congress of} European ORL-HNS, October 11, 2017, Barcelona, Spain.

\section{Corresponding Author:}

Jeyasakthy Saniasiaya; shakthy_18@yahoo.com

Received Date: 28.10 .2018

Accepted Date: 25.07.2019

Content of this journal is licensed under a Creative Commons Attribution 4.0 International License.

Available online at www.turkarchotolaryngol.net
Paediatric germ cell tumor is composed of various neoplasms which exhibit capricious clinical presentation and histological features depending on the age and the area of presentation. Yolk sac tumor is an extremely rare malignant tumor of embryonic origin which usually arises from the gonads. Its manifestation in the head and neck region is extremely rare. Here, we report a rare case of the malignant transformation of mature teratoma into yolk sac tumor of the neck in an infant. Diagnosis was confirmed following histopathological examination of the neck mass along with marked increase of the serum alpha-fetoprotein. The child unfortunately succumbed prior to chemotherapy. We highlight the challenge we faced in diagnosing and managing this rare entity. We would also like to recommend serial monitoring of serum alpha-fetoprotein in all patients with mature teratoma to detect malignant transformation early.

Keywords: Germ cell tumor, yolk sac tumor, teratoma, malignant transformation

\section{Introduction}

Yolk sac tumor (YST), also known as endodermal sinus tumor, accounts for 4-6\% of all malignant lesions that arise mostly in the ovaries and testes (1). It is also the most common malignant germ cell tumor that occurs in association with teratoma (2). In the head and neck region, YST has been reported to involve the nasopharynx, the sinonasal tract, the orbit, the ear and the parotid gland (3). We are reporting a rare case of malignant transformation of a mature teratoma into YST of the neck. We discuss a YST of the neck in an infant, its diagnostic challenges and management with the presented case. To our knowledge, this is the first case reported in the literature available in English on the malignant transformation of mature teratoma into YST in the neck.

\section{Case Presentation}

A newborn male patient was referred to the Otorhinolaryngology department for a huge left neck swelling (Figure 1). Antenatal scan revealed a small, left-sided cystic swelling. The child was de- livered via elective lower-section Caesarean section. The child exhibited no obstructive symptoms and remained stable under room air. Besides, the child had no other syndromic features or any other gonad deformity. His serum alpha-fetoprotein level was $143,984 \mathrm{ng} / \mathrm{mL}$.

Computed tomography of the brain and the neck revealed a huge multiseptated cystic mass extending from the left base of the skull up to the submandibular region, measuring $10.3 \times 16.5 \times 16.0 \mathrm{~cm}$ with extension into the left parapharyngeal and the infratemporal space (Figure 2). In the light of the patient's presentation, clinical examination along with imaging, a preliminary diagnosis of cystic hygroma was made. The child was subsequently given three doses of sclerotherapy with OK-432 at one-month intervals with no notable complication. However, the regression of the neck mass after the treatment was minimal.

His parents were offered an excision of the left neck mass and they agreed. Intraoperatively, two huge 


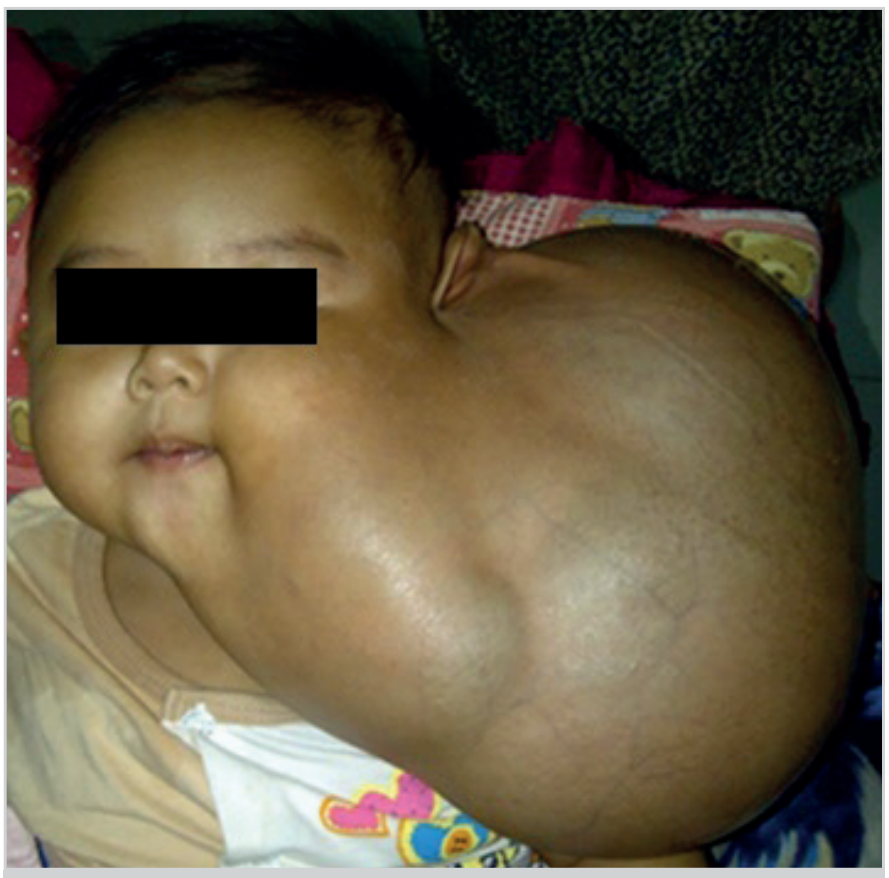

Figure 1. Left huge neck swelling

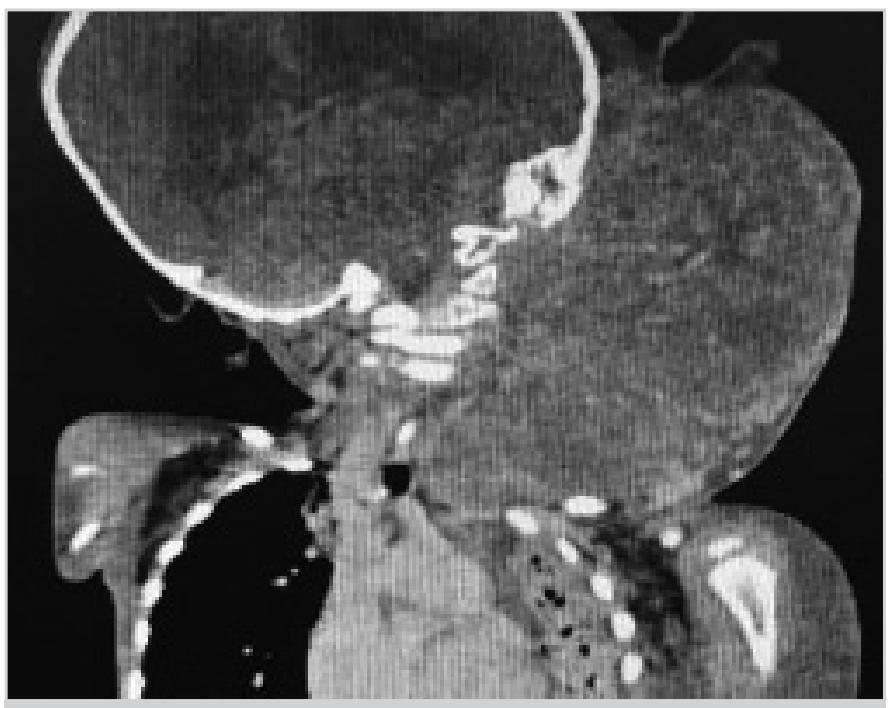

Figure 2. Computed tomography of the neck showing huge multiseptated cystic mass from the left base of skull to the submandibular region, measuring $10.3 \times 16.5 \times 16.0 \mathrm{~cm}$ with extension into the left parapharyngeal and the infratemporal space

cystic masses were excised completely. The first excised mass was more superficial, measuring $14 \times 18 \mathrm{~cm}$, while the second mass was excised from the left parapharyngeal space, measuring $7 x 7 \mathrm{~cm}$.

Post-operatively, the child was well with no complications and was discharged on the next day. Histopathological examination of the excised mass revealed cystic lesion lined partly with stratified squamous epithelium and respiratory-type epithelium with small solid component and neurological tissues. Mature components of endodermal, ectodermal and mesodermal tissues were seen--which is suggestive of a mature teratoma.

In the subsequent follow-up period, the child showed no signs of recurrence. Alpha-fetoprotein level taken three months af-
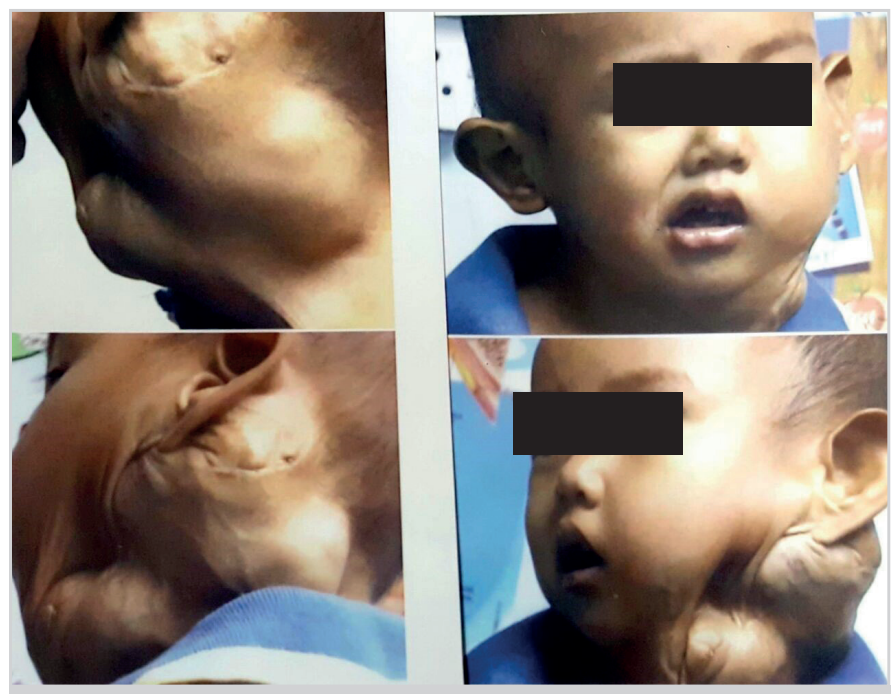

Figure 3. Lobulated cystic swelling extending from the left postauricular region to the clavicle, firm, non-tender with flabby overlying skin with facial nerve palsy Grade II

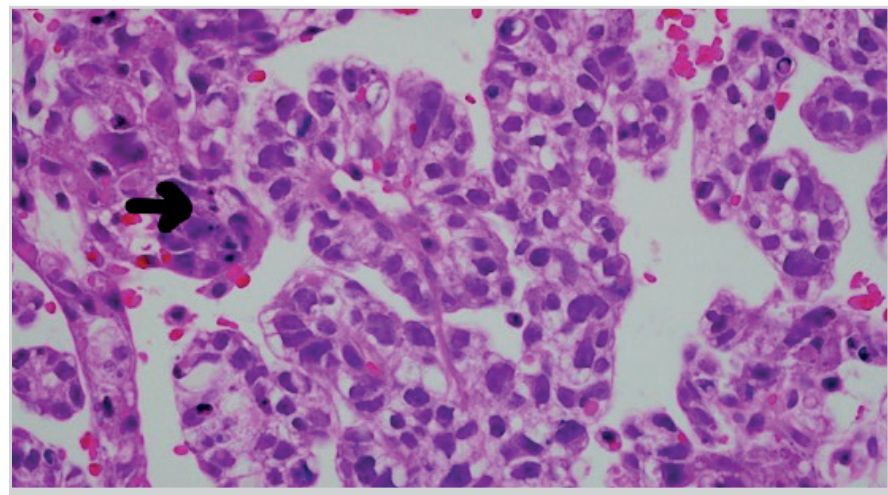

Figure 4. Schiller-Duval body (arrow) which consists of a central vessel surrounded by tumor cells (H\&E X400 magnification)

ter the excision was within normal range $(<8.5 \mathrm{ng} / \mathrm{mL})$. The child was completely asymptomatic until about one year later when his parents noted recurrence of left neck swelling which progressively increased in size. Concurrently, a reddish friable mass was protruding from the left ear canal and left-sided facial weakness was noted. Neck examination revealed lobulated, cystic, non-tender swelling extending from the post-auricular region up to the clavicle (Figure 3). A reddish mass was seen protruding from the left ear canal which bled upon touch. The patient also had lower motor neuron facial nerve palsy House Brackman Grade II.

The child was admitted and underwent incisional biopsy. Computed tomography scanning from the brain down to the pelvis revealed an extensive, multilobulated, heterogeneously enhancing mass at the left neck superiorly, insinuating into the left temporal bone involving the left facial nerve with extension into the left temporal lobe; inferiorly extending into the anterior mid-thorax and medially displacing the left parapharyngeal space. Serum alpha-fetoprotein level was raised (380.86 $\mathrm{ng} / \mathrm{mL}$ ). Histopathological examination of the mass revealed tumor tissue arranged in sinusoidal growth pattern with mi- 
crocyst formation and papillary configuration. Characteristic Schiller-Duval body was noted with no concurrent features of teratoma (Figure 4). After discussing with the pathologist and the radiologist, diagnosis of malignant transformation of mature teratoma to YST with intracranial extension was made. A repeat serum alpha-fetoprotein level taken after two weeks was 16,353 $\mathrm{ng} / \mathrm{mL}$, which showed a marked increase. Chemotherapy was planned, however, the child unfortunately succumbed due to sepsis. Prior to his passing his serum alpha-fetoprotein level was $1,225,728 \mathrm{ng} / \mathrm{mL}$. Informed consent was obtained from the parents for this publication.

\section{Discussion}

The term endodermal sinus tumor was first coined by Teilum (4) in 1959. YST, or endodermal sinus tumor, is a malignant germ cell tumor which accounts for $20 \%$ of all malignant germ cell tumors. Despite the countless theories that have been suggested to date regarding the extragonadal yolk sac tumor, detachment of germ cells from the gonadal crest during embryogenesis, followed by malignant transformation of these cells remains to be the most plausible theory (5). Germ cell tumor oftentimes affects males (6) which is consistent with our patient.

Diagnosis is made via histopathological examination and immunochemistry study. In our case, initial histopathological examination of the excised neck mass reported mature teratoma. However, repeat biopsy of the neck mass one year after the initial excision was consistent with YST. Pathognomonic histological features of the YST include flat to cuboidal tumor cells centered around blood vessels forming characteristic Schiller-Duval bodies (5). These were also present in our case. Immunohistochemistry study, which is helpful in diagnosing this entity, includes placental alkaline phosphatase (PLAP), alpha-fetoprotein, cytokeratin, epithelial membrane antigen (7).

As this entity can only be diagnosed histologically, histological differential diagnosis includes other germ cell tumors; seminoma and embryonal carcinoma, juvenile granulosa cell tumor, malignant rhabdoid tumor, other poorly differentiated tumors, metastatic papillary epithelial and epithelioid mesenchymal tumors (8).

Although YST is the most common malignant germ cell tumor, it oftentimes occurs in association with teratoma (2). Malignant transformation of extragonadal mature teratoma has also been reported. In our patient, histopathological examination revealed malignant transformation of mature teratoma into yolk sac tumor. Similarly, Mamoon et al. (7) reported a case of malignant transformation of mature teratoma into YST in the parapharyngeal space. Byard et al. (9) reported another case in which a mature teratoma excised from the nasopharynx transformed into YST three years later. In all the cases reported, unfortunately, following a malignant transformation into YST, the infants succumbed early.

Yolk sac tumor is known to secrete alpha-fetoprotein. Hence, serum alpha-fetoprotein is an important marker for monitoring the progress of the disease, the response to treatment, the prognosis, as well as for detecting recurrence or metastasis of the disease (6). This was the case in our patient, serum alpha-fetoprotein level, which was markedly high upon birth, normalized in the three months after the first excision. However, one year later, following the recurrence of the mass, the serum alpha-fetoprotein level showed a drastic rise of serum titer to $380 \mathrm{ng} /$ $\mathrm{mL}$, then two-weeks later the level increased to $16,353 \mathrm{ng} / \mathrm{mL}$ and prior to his passing, the serum alpha-fetoprotein level was $1,225,728 \mathrm{ng} / \mathrm{mL}$. It's worth noting that serum alpha-fetoprotein levels are usually elevated in newborns and return to a normal level at around four months of age. Immunohistochemistry of alpha-fetoprotein plays an important role as a tumor marker for diagnosis and follow-up (10).

Yolk sac tumor exhibits an extremely aggressive nature and is commonly unresectable upon diagnosis in the presence of local recurrence or early metastasis $(2,11)$. The most common sites of metastasis that have been reported are the lungs, followed by the liver, the lymph nodes and the bones (6). In our case, the patient presented with an extensive mass one-year after the initial excision with intracranial extension and facial nerve palsy.

To date there is no consensus on the mode of treatment of YST, owing to its rarity. However, many authors have recommended surgical resection with adjuvant chemotherapy as the main method of treatment especially in YSTs of the gonads (5). Filho et al. (6) reported that, postoperative adjuvant radiotherapy has satisfactory outcome amongst patients with head and neck involvement. Our patient was planned for chemotherapy, however, succumbed as a result of sepsis. Chemotherapeutic agents using a BEP regime, which is composed of a cocktail of bleomycin, etoposide and cisplatin, have been reported by some authors to have a significantly good outcome (1). Overall prognosis is relatively poor in children with extragonadal tumor as compared to gonadal tumor.

\section{Conclusion}

Yolk sac tumor, albeit rare, warrants attention amongst clinicians as early diagnosis has significant influence on the clinical outcome and the survival amongst infants. Its rarity poses great challenge to physicians, especially regarding the mode of treatment. We would like to emphasize that treatment ought to be individualized and tailored according to the patient.

Informed Consent: Written informed consent was obtained from the parents of the patient.

Peer-review: Externally peer-reviewed.

Author Contributions: Concept - J.S., S.S.A.H.; Design - J.S., S.S.A.H., H.M.; Supervision - S.S.A.H., H.M., N.Z.; Resource - J.S., W.N.N.W.A.W.; Materials - J.S., W.N.N.W.A.W.; Data Collection and/or Processing - J.S., S.S.A.H.; Analysis and/or Interpretation J.S., S.S.A.H.; Literature Search - J.S., S.S.A.H., H.M.; Writing - J.S., S.S.A.H.; Critical Reviews - S.S.A.H., H.M., N.Z.

Conflict of Interest: The authors have no conflicts of interest to declare. 
Financial Disclosure: The authors declared that this study has received no financial support.

\section{References}

1. Kusumakumari P, Geetha N, Chellam VG, Nair MK. Endodermal sinus tumors in the head and neck region. Med Pediatr Oncol 1997; 29: 303-7.

2. Roy M, Agarwal S, Bakhshi S, Bhalla AS. Extragonadal yolk sac tumor of the head and neck region: A report of two cases. J Cancer Res Ther 2015; 11: 1000-2. [CrossRef]

3. Arumugam D, Thandavarayan P, Chidambaram L, Boj S, Marudasalam S. Primary nasopharyngeal yolk sac tumor: A case report. J Clin Diagn Res 2016; 10: 6-7. [CrossRef]

4. Teilum G. Endodermal sinus tumours of the ovary and testis. Comparative morphogenesis of the so-called mesonephroma ovarii (Schiller) and extraembryonic (yolk sac-allantoic) structures of the rat's placenta. Cancer 1959; 12: 1092-105.
5. Zhang Q Huang Y, Bao CY, Li LJ. Yolk sac tumour involving floor of mouth: case report. Br J Oral Maxillofac Surg 2013; 51: 67-9. [CrossRef]

6. Filho BC, McHugh JB, Carrau RL, Kassam AB. Yolk sac tumor in the nasal cavity. Am J Otolaryngol 2008; 29: 250-4. [CrossRef]

7. Mamoon N, Jaffri SA, Ilahi F, Muzaffar K, Iqbal Y, Akhter N, et al. Yolk sac tumour arising in mature teratoma in the parapharyngeal space. J Pak Med Assoc 2011; 61: 1025-7.

8. Furtado LV, Leventaki V, Layfield LJ, Lowichik A, Muntz HR, Physher TJ. Yolk sac tumor of the thyroid gland: A case report. Pediatr Dev Pathol 2011; 14: 475-9. [CrossRef]

9. Byard RW, Smith CR, Chan HSL. Endodermal sinus tumor of the nasopharynx and previous mature congenital teratoma. Fetal Pediatr Pathol 1991; 11: 297-302. [CrossRef]

10. Chen Z, Zheng P, Huang S, Zhang D. Yolk sac tumor of upper lip: A case report. Oncol Lett 2017; 14: 6238-42. [CrossRef]

11. Kutluhan A, Uğraş S, Akman E. Endodermal sinus (yolk sac) tumor of oral cavity originating from gingiva. Auris Nasus Larynx 1998; 25: 459-62. [CrossRef] 